Reprod. Nutr. Dévelop., 1988, 28 (1), 129-130.

\title{
Etude ultrastructurale d'un champignon phycomycète anaérobie strict du rumen : Piromonas communis
}

Brigitte GAILLARD, Anne CITRON, A. BRETON

Laboratoire de Microbiologie

I.N.R.A., Theix, 63122 Ceyrat, France.

Summary. The ultrastructural observation of Piromonas communis showed the presence of hydrogenosomes and associated ribosomes in the form of aggregates or helices; mitochondria were absent.

Piromonas communis présente un cycle de vie comportant une forme mobile flagellée à l'origine d'un thalle composé d'un seul sporocyste pourvu de rhizoïdes.

Matériel et méthodes. Les échantillons ont été traités de façon classique Iglutaraldehyde $3 \%$ et tétroxyde d'osmium $1 \%$ dans du tampon cacodylate, inclusion en résine époxy TAAB pour la MET).

Résultats et discussion. Piromonas se caractérise par des sporocystes piriformes ancrés au substrat par des rhizoïdes (fig. 1), qui différencient des spores uniflagellées (fig. 2). En MET, on retrouve la forme allongée du sporocyste délimité par une paroi épaisse et lacuneuse, avec des ébauches de spores individualisées par une membrane discontinue (fig. 3).

La spore de Piromonas est munie d'une fine paroi, d'une membrane plasmique et renferme un noyau. Elle possède deux types d'organites: 1 . des organites réunis sous formes d'agrégats globulaires ou disposés par 5 ou 6 suivant une hélice (fig. 4), qui correspondent aux ribosomes décrits par Orpin et Munn (1986) chez Neocallimastix ; 2. des organites peu denses aux électrons, à contenu amorphe (fig. 5), observés chez Neocallimastix patriciarum (Orpin et Munn 1986) et assimilés aux hydrogénosomes.

Les rhizoïdes (fig. 6) montrent une paroi couverte extérieurement de granulations de nature inconnue et à l'intérieur, on distingue des formations membranaires de taille et de forme variables.

Conclusion. Piromonas communis, présente une structure tout à fait comparable à celle décrite chez Neocallimastix. Ces résultats joints à ceux connus sur les activités métaboliques (Fonty et Breton, non publié) confirment l'étroite parenté des différents genres de champignons du rumen. 


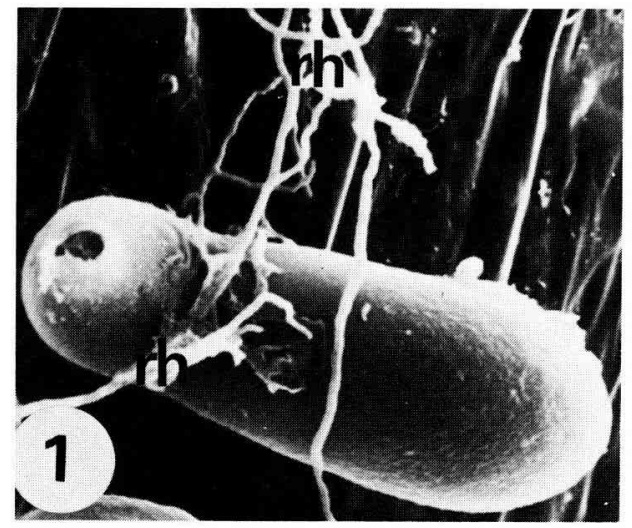

FIG. 1. - Sporocyste de Piromonas communis avec rhizoïdes (rh) en M.E.B. $\times 2700$.

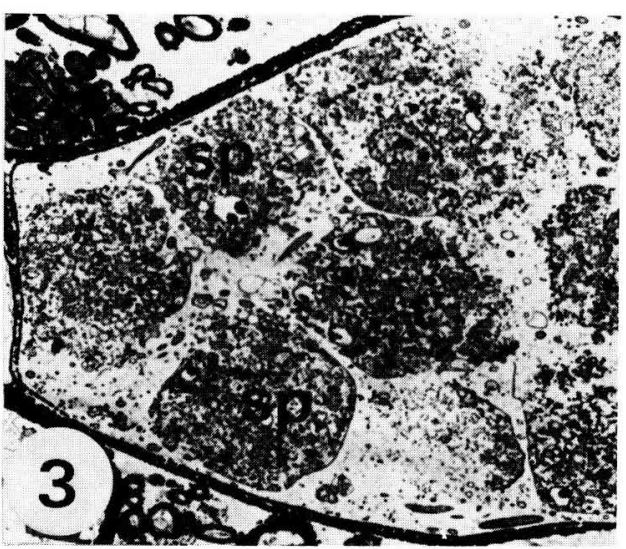

FIG. 3. - Sporocyste de Piromonas communis avec les ébauches des spores (sp) en M.E.T. $\times$ 3676 .

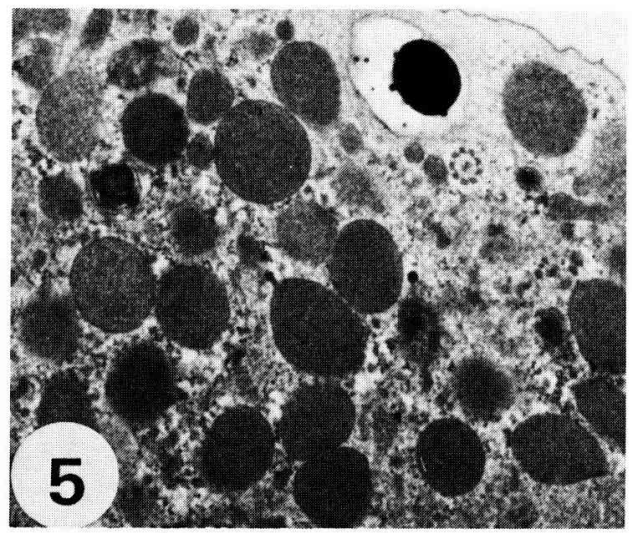

FIG. 5. - Organites peu denses: les hydrogénosomes en M.E.T. $\times 21000$.

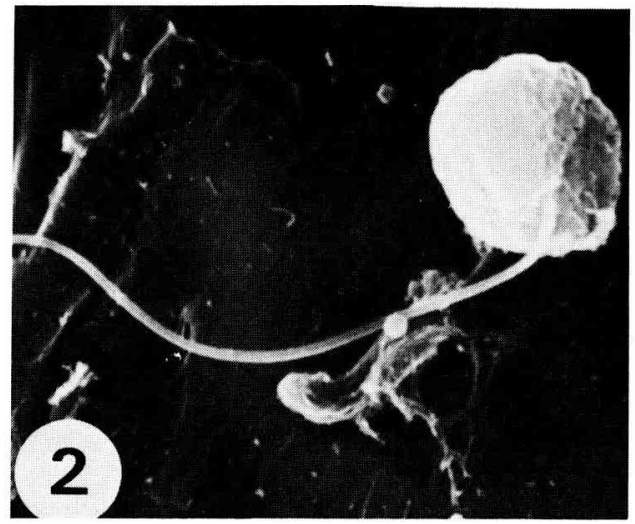

FIG. 2. - Spore uni-flagellée de Piromonas communis en M.E.B. $\times 19300$.

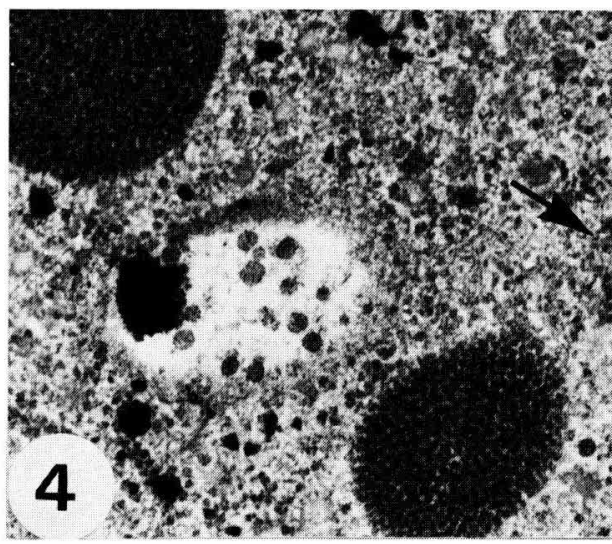

FIG. 4. - Ribosomes sous forme d'agrégats ou par 5 ou $6(>)$ en M.E.T. $\times 63000$.

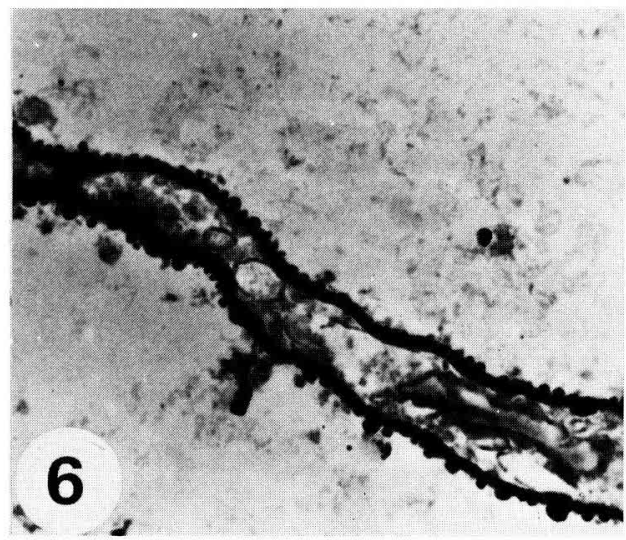

FIG. 6. - Rhizoïdes de Piromonas communis en M.E.T. $\times 28600$. 